\title{
Burnout syndrome in healthcare professionals
}

\author{
G Jagannath
}

H.NO- 3-3-108/153, Phase 2, New Friends Colony, Hyderguda, Attapur, Rajendranagar, R.R District, Hyderabad, Telangana, India

\author{
*Corresponding Author: Jagannath G \\ Email: jaganth1900@yahoo.com
}

"Never overestimate the strength of the torchbearer's arm, for even the strongest arms grow weary"

\section{Introduction}

Burnout is the result of chronic stress in workplace which has not been dealt successfully. ${ }^{1}$ It is characterized by emotional exhaustion, depersonalization and reduced personal accomplishment. $^{2}$

Psychoanalyst Freudenberger, ${ }^{3}$ published one of the first scientific descriptions of the burnout syndrome as psychiatric and physical breakdown.

In 1981, Maslach introduced an instrument for measuring burnout, the Maslach Burnout Inventory ${ }^{4,5}$ which is widely used even today.

\section{Burnout Syndrome}

Burnout syndrome is a state of emotional, physical and mental exhaustion caused by excessive and prolonged work related stress. It is a work-related constellation of symptoms that is diagnosed in individuals without any prior history of psychological or psychiatric disorders. Freudenberger described its development in a 12-stage model (Fig. 1). ${ }^{6}$ Currently this model has been simplified and a 5-stage model is most frequently used. This 5-stage model is depicted in the Fig. 2.
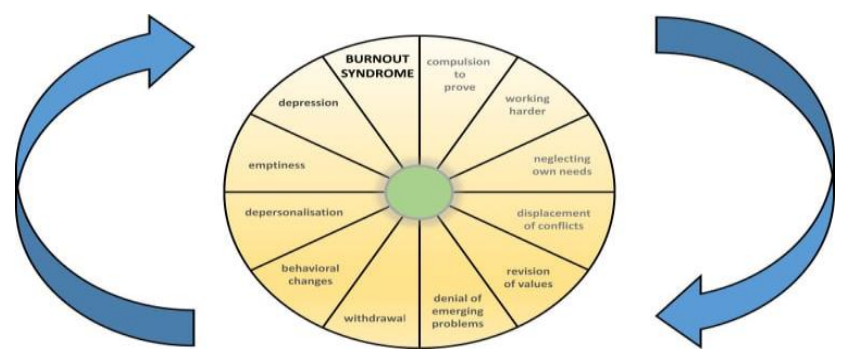

Fig. 1:

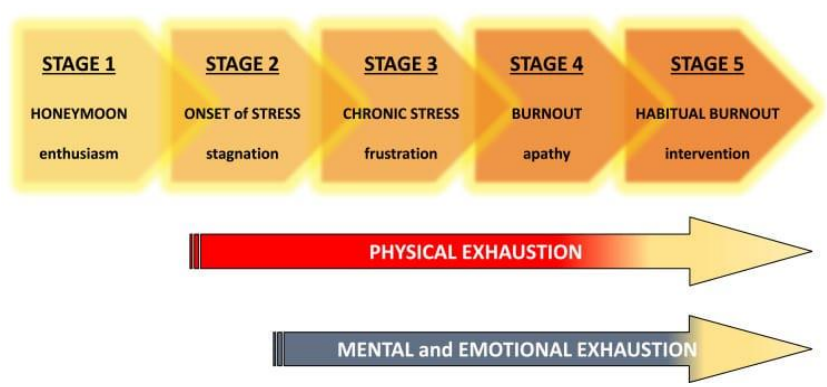

Fig. 2:
Initially individuals feel emotional stress and increasing jobrelated disillusionment. Subsequently, they lose the ability to adapt to the work environment and display negative attitude towards their job, their co-workers, and their clients. $^{7}$

The decisive elements of burnout syndrome are exhaustion, depersonalization, and reduced satisfaction in performance. $^{8}$

\section{Etiopathogenesis}

The etiopathogenesis of burnout is multifactorial. It is triggered by a discrepancy between the expectations and ideals of the employee and the actual requirements of their position. ${ }^{7}$ It is best explained by psychological explanatory models. The job demand-control model focuses on job task profile (job demand vs control, Fig. 3) and effort-reward imbalance model focuses on the work contract (effort vs reward, Fig. 4). ${ }^{9,10}$

\section{ICD-10 Vs DSM}

In the $10^{\text {th }}$ revision of the International Classification of Diseases (ICD 10) the term 'burnout' was described under Z.73.0 as 'Burnout-state of total exhaustion'. ${ }^{11}$ Burnout emerged as a condition in ICD-10 and 11 as occupational stress. So far it is not an entity in DSM and is considered among adjustment and stress related disorder. ${ }^{12}$

\section{Magnitude of the Problem}

Healthcare professionals at the front line of care (family medicine, emergency medicine, general internal medicine, and critical care) report the highest rates of Burnout in excess of $40 \%$. Working in an Intensive Care Unit (ICU) can be especially stressful due to high patient morbidity and mortality. Challenging daily work routines, and routine encounters with traumatic and ethical issues will increase the stress. This level of nearly continuous stress can rapidly accelerate when caregivers perceive that there is insufficient time or limited resources to properly care for patients. Unfortunately, critical healthcare professionals have one of the highest rates of burnout. Based upon multiple studies, approximately $25-33 \%$ of critical care nurses manifest symptoms of severe burnout, and up to $86 \%$ have at least one of the three classic symptoms. When compared to other types of nurses, burnout occurs more commonly in critical care nurses. Burnout Syndrome is also common in critical care physicians. ${ }^{13} \mathrm{Up}$ to $45 \%$ of critical care physicians reported symptoms of severe Burnout. Among pediatric 
critical care physicians the prevalence of Burnout is $71 \%$ which is more than twice the rate in general pediatricians. ${ }^{14}$ Burnout syndrome is highly common among resident doctors, as they are new to the field and often considered incompetent by patients and seniors and have tremendous work load cum responsibility. On an average 2/3rd of residents at one time and $90 \%$ of students in the period of their residency have a history similar to Burnout syndrome. ${ }^{15}$

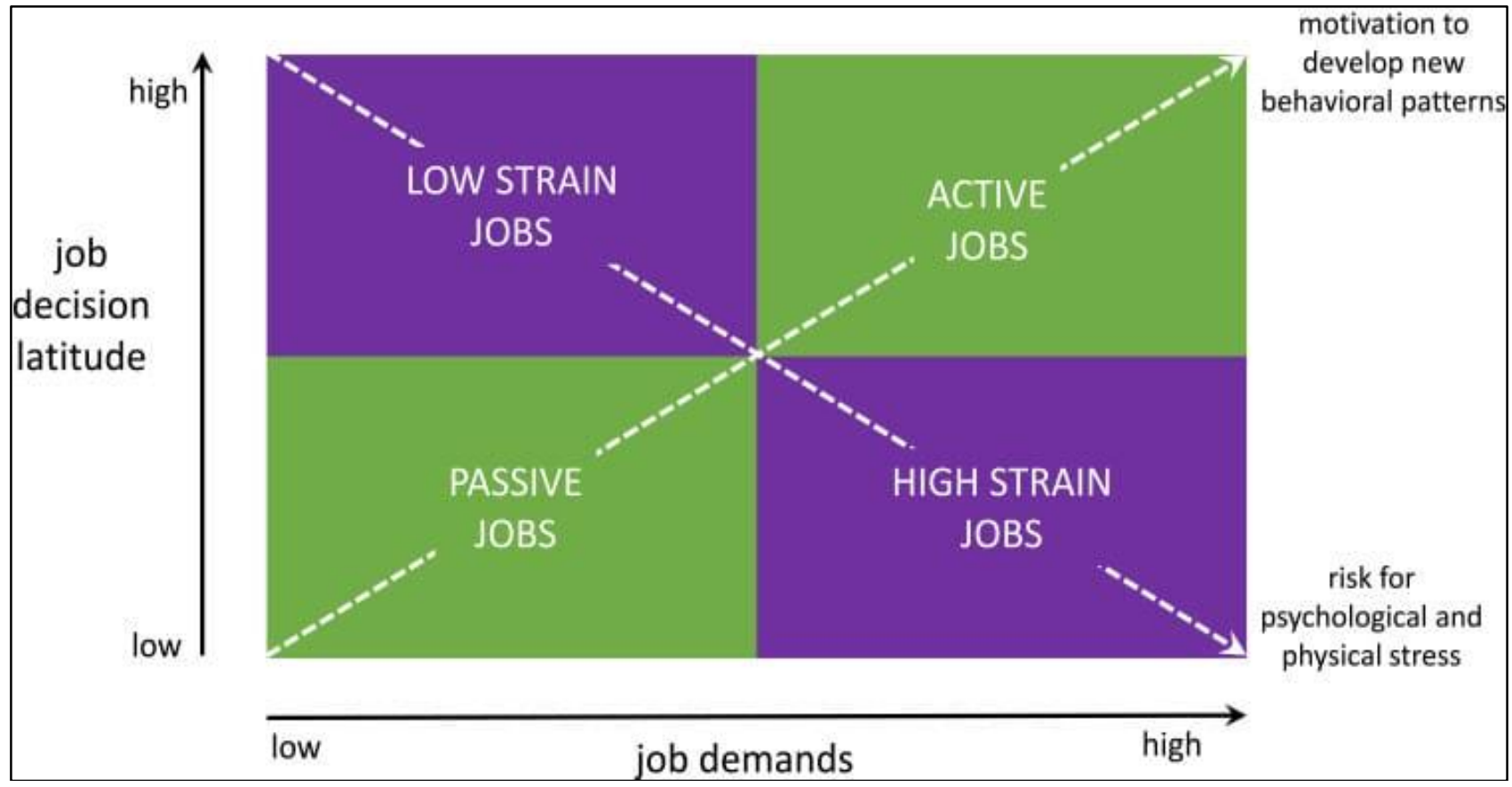

Fig. 3:

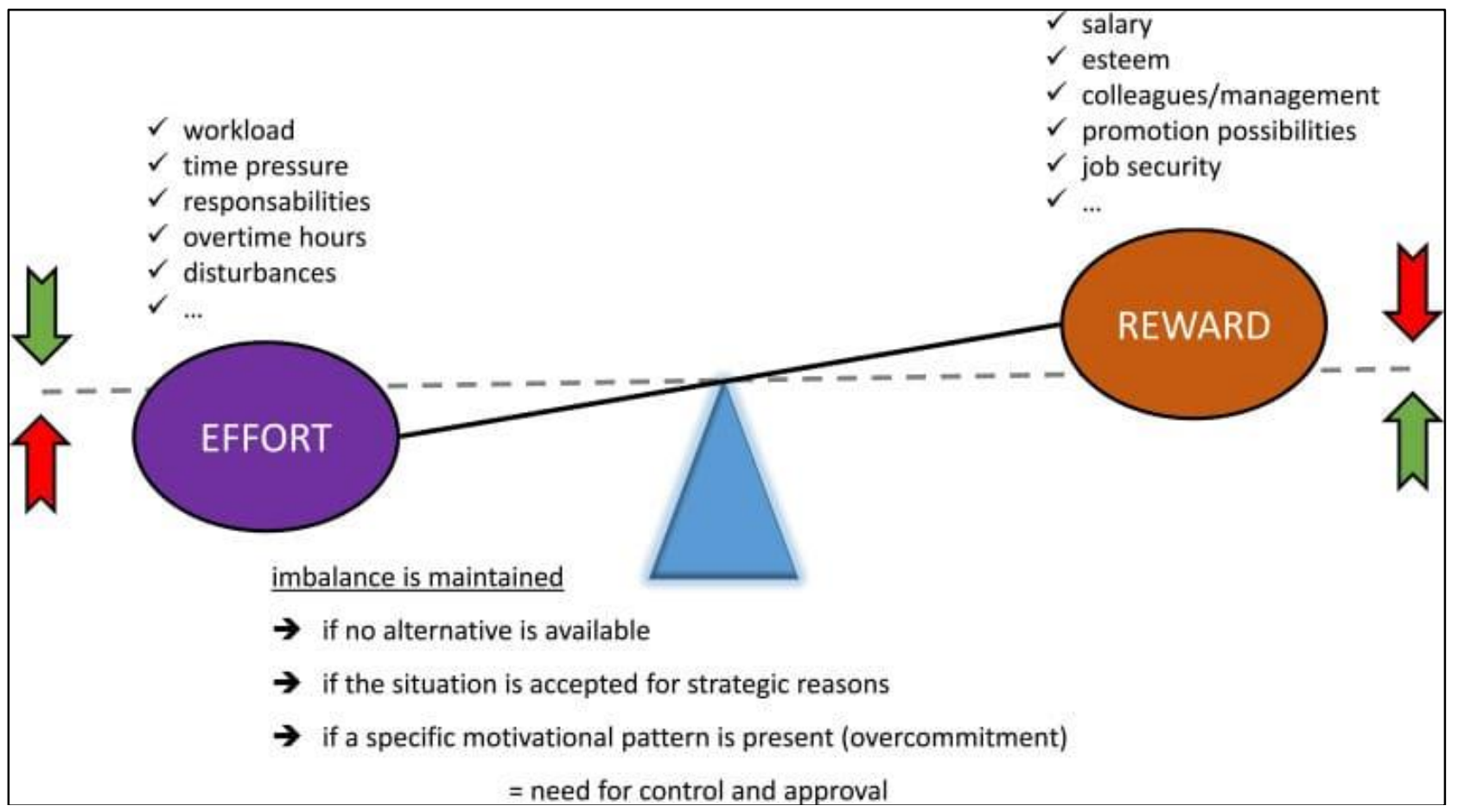

Fig. 4: 
Among other professions where discipline, responsibility and workload is enormous for example in army, bureaucrats, students pursuing higher education, law firms and among business class people, the magnitude of burnout differs but it is invariably present. The reasons may be competition, workload, personal expectations and social image etc. Although, burnout is related to occupational stress, the attitude of person, their behavior and coping skills also matters a lot in dealing with the stress.

\section{Who is an Exception...}

It is highly prevalent among health care professionals, army professionals, researchers, banking and finance sector and teachers in some part of the world and as matter of fact, in any field.

\section{Risk Factors in Health Care Professionals}

Risk factors vary in nature, severity, and as per the kind of workplace. For instance, in health care settings, especially in India huge population, scarce health care workers, poor infrastructure, less incentives, frequent end-of-life events, risk of getting infected, a thankless attitude of patients and family and fear of being blamed for any mis-happenings have a crucial role in genesis of burnout syndrome. ${ }^{16}$

\section{Individual risk factors}

1. Younger age

2. Idealistic view for the self and world

3. Rigid or less flexible attitude

4. Financial issues

5. Physical health condition amounting to difficulty in doing hard work for longer periods

6. Poor self-esteem of individual

7. Maladaptive coping mechanism

8. Type A Personality traits

9. Unrealistically high expectations

\section{Organizational risk factors}

1. Heavy workload

2. Poor management

3. Conflicts with co-workers

4. Lack of control or input

5. Effort- reward imbalance

6. Favoritism and discrimination leading to partiality

7. Lack of proper communication

8. Lower pay scale as compared to work load and working conditions

\section{Burnout in Current Pandemic State}

Current pandemic and burnout syndrome in India

In today's context, when the whole world is facing immense crisis due to the current pandemic, this syndrome has been observed in almost all the frontline workers. The doctors, nurses, OT and Laboratory staff, hospital cleaning and maintenance staff, police personnel, security personnel, sanitation workers, retailers and vendors and in people from various streams those who have been doing their job in protecting the human race from this pandemic are adversely affected.
Work load has increased manifold, while the infrastructure remains compromised. Nationwide, initially there was lack of PPEs and basic safety materials like gloves and sanitizers. The nature of virus has also remained mysteriously unexplored for quite a long time and the patients who are infected were treated on trial error basis without proper treatment guidelines.

In the midst of all the uncertainties and risk of being infected and to prevent further transmission to the family members, patients, fellow doctors, nurses and other health care staff frontline workers have opted to remain in hospitals under tremendous stress.

It goes beyond saying that working for long hours, staying away from home, being exposed to false information across the world and potential threat of being mis-treated by patient's family members, there is increased risk of fatigue and burnout syndrome in healthcare workers during COVID 19 pandemic. ${ }^{17}$

\section{Symptoms}

The symptoms of burnout patients are usually multidimensional with several psychiatric, psychosomatic, somatic and social disorders. The most common symptoms are concentration difficulties, memory disturbances, lack of drive and personality change, in addition to chronic fatigue $^{18}$. Severe disturbances like anxiety and depression, suicide, addictions (e.g. alcohol, sedatives) were also noted in few. Common somatic symptoms are headaches, gastrointestinal disorders (irritable stomach, diarrhoea), or cardiovascular disturbances such as tachycardia, arrhythmia, and hypertonia were noted. Symptoms in different stages of burnout are shown in the Fig. 5.

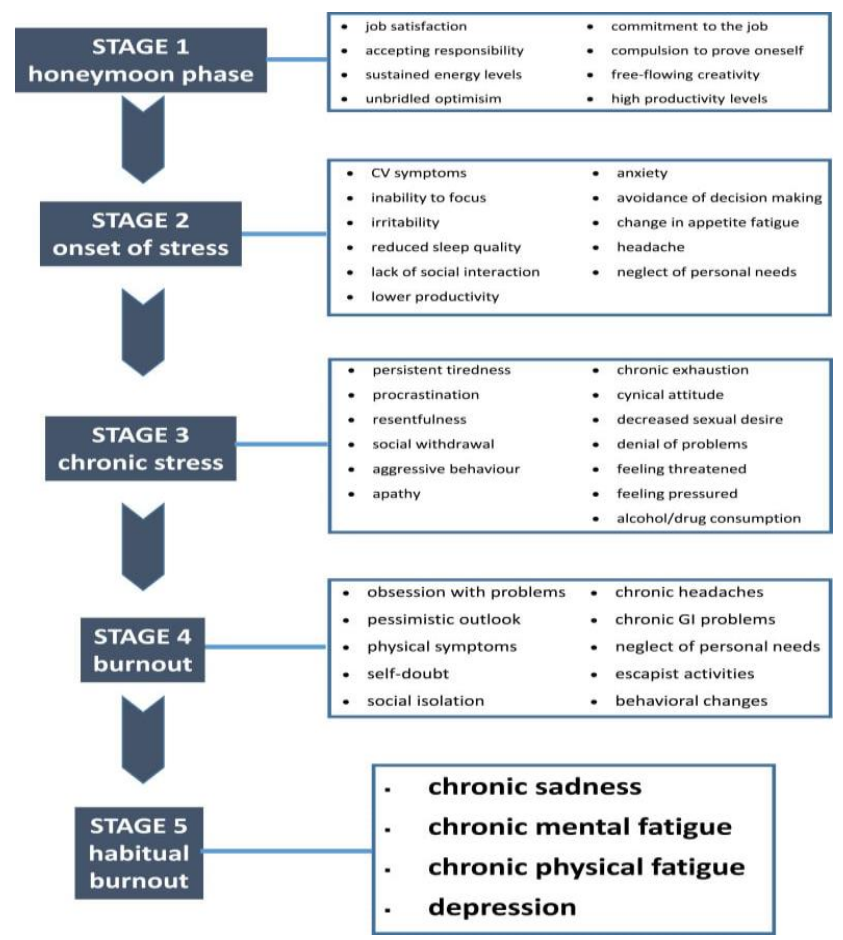

Fig. 5: 


\section{Consequences of Burnout Syndrome}

Burnout syndrome in critical healthcare professionals may result in post-traumatic stress disorder (PTSD), alcohol abuse, and even suicidal ideation. Exhaustion is normal reaction to stress. Burnout may increase the risk of someone developing depression. ${ }^{19}$ Burnout also results in decreased clinical effectiveness and poor work performance that may impact patient care.

Burnout in nurses is associated with low quality of care, lower patient satisfaction, increased number of medical errors, increased rates of health-care associated infections and higher 30-day mortality rates. ${ }^{20}$

There is a strong "dose-response" and "bidirectional" relationship between burnout scores and medical errors: errors lead to distress and distress leads to errors.

\section{Assessment}

American psychologist, Christina Maslach, developed an inventory to assess or rate burnout features in a person, known as Maslach Burnout Inventory (MBI-HS). HS stands for health care staff. The MBI-HS is a 22-item self-report questionnaire that consists of three independently scored dimensions (emotional exhaustion, depersonalization and a lack of personal accomplishment). ${ }^{21}$

Potential treatment or prevention for burnout syndrome Evidence-based interventions to treat and prevent Burnout are currently not available in critical healthcare professionals. Interventions focused on both the individual and organization should be developed. Resilience is a psychological characteristic that enables an individual to adjust in a healthy way after a traumatic event. Resilience has been recognized as a mechanism to mitigate the symptoms of PTSD following trauma and treat Burnout. While there are innate or inherent qualities of resilience, some qualities of resilience can be learned and imbibed. Examples of resiliency techniques include: a) being optimistic, b) developing cognitive flexibility, c) establishing and maintaining a supportive social network, d) mindfulness training, and e) exercising. Organizational interventions should be aimed at sustaining a healthy work environment. The six standards include:

1. Having skilled communication

2. Appropriate staffing

3. Collaboration

4. Meaningful recognition

5. Effective decision-making

6. Authentic leadership

It is important that one should understand a few warning signs of burnout, so that he/ she can take appropriate steps to avoid serious consequences of it. As burnout syndrome significantly reduces the functioning of an individual, it impairs the "quality of Life". It also simultaneously reduces the productivity and outcome, which is essential for institutional optimal functioning. It is therefore a joint responsibility of employee and employer to look forward to actively mitigate Burnout.

\section{Methods to mitigate Burnout Syndrome}

1. Understand that there are ways to manage your workrelated stressors that can put you at risk for burnout syndrome.

2. Engage the support of management, co-workers and friends that may help you cope with stress at work.

3. Take breaks from work. Go outside for a walk for fresh air. Exercise is known to enhance your energy and mood.

4. Understand and learn to enjoy the work and focus on your interests and passions.

5. Practice techniques such as reframing and optimism while dealing with stressful work.

\section{Conclusion}

High-quality controlled studies on burnout syndrome are lacking. In view of current lack of knowledge about what is called burnout, the term should not be used as medical diagnosis or as a basis for decisions regarding disability or other socioeconomic matters. ${ }^{22}$

Early recognition of symptoms, providing healthy work environment and teaching resilience techniques to mitigate stress will go a long way in protecting our professional colleagues from getting affected by BURNOUT SYNDOROME.

\section{Source of Funding}

None.

\section{Conflict of Interest}

The authors declare that there is no conflict of interest.

\section{References}

1. Hert SD. Burnout in healthcare workers: Prevalance, Impact and Preventive strategies. Local Reg Anesth. 2020;13:171-83.

2. Polikandrioti M. Editorial article: Burnout syndrome. Health Sci J. 2009;3(4):195-7.

3. Freudenberger HJ. Staff burnout. J Soc Issues 1974; 30:15965.

4. Burisch M. Das Burnout-Syndrome-Theorie der inneren Erschopfung 2. Auflage. Berlin, Heidelberg: Springer Verlag, 1994.

5. Maslach C, Jackson SE. The measurement of experienced burnout. J Occup Behav. 1981;2:99-113.

6. Freudenberger HJ. Counseling and dynamics: treating the end stage person In: Jones JW, editor. The Burnout Syndrome. Park Ridge III: London House Press;1982.

7. Moss M, Good VS, Gozal D, Kleinpell R, Sessler CN. A Critical Care Societies Collaborative Statement: Burnout Syndrome in Critical Care Health-care Professionals. A Call for Action. Am J Respir Crit Care Med. 2016;194(1):106-13.

8. Savicki V, Cooley EJ. Theoretical and research considerations of burnout. Child Youth Serv Rev. 1983;5:227-38.

9. Karasek RA. Job demands, job decision latitude and mental strain. Implications for job redesign. Admsci $Q$. 1979;24:285308

10. Siegrist J, Peter R. The effort -reward imbalance model In. Schnall P, Belkic K, Landsbergis P, Baker D, editors. The workplace and cardiovascular Disease. Occupational medicine state of the Art Reviews. 2000;15:83-7. 
11. Kakiashvili T, Leszek J, Rutkowski K. The medical perspective on burnout. Int J Occup Med Environ Health. 2013;26(3):401-12

12. International classification of Diseases-10th Edition.

13. Moss M, Good VS, Gozal D, Kleinpell R, Sessler CN .A critical care societies collaborative statement: burnout syndrome in critical care health care professionals a call for action. Am J Respir Crit Care Med. 2016:194:106-13.

14. Mealer M, Conrad D, Evans J, Jooste K, Solyntjes J, Rothbaum B, et al. Feasibility and Acceptability of a Resilience Training Program for Intensive Care Unit Nurses. Am J Crit Care. 2014;23(6):e97-e105.

15. Clever LH. Who is sicker: patients-or residents? Residents' distress and the care of patients. Ann Intern Med.2002;136391393

16. Mealer M et al (2014). Feasibility and acceptability of a resilience training program for intensive care unit nurses. American Journal of critical care, 23(6), 97-105.

17. Sasangohar F, Jones SL, Masud FN, Vahidy FS, Kash BA. Provider Burnout and Fatigue During the COVID-19 Pandemic: Lessons Learned From a High-Volume Intensive Care Unit. Anesth Analg. 2020;131:106-11
18. Weber A, Jaekel-Reinhard A. Burnout syndrome: a disease of modern societies? Occup Med. 2000;50(7):512-7.

19. Informed Health.org[Internet]. Cologue, Germany: Institute for Quality and efficiency in healthcare(IQWIG); 2006-

Depression. What is burnout? 2020 June 18

20. Colligan TW, Colligan MSW, Higgins M, workplace stressetiology and consequences. $J$ Workplace Behav Health. 2006;21:89-97.

21. Maslach C, Jackson SE, Leiter MP. Maslach Burnout Inventory Manual. $3^{\text {rd }}$ ed. Palo Alto, CA: Consulting Psychologists Press; 1996.

22. Kaschka WP, Korczak D, Broich K. Burnout- a fashionable diagnosis. Dtsch Arztebl Int. 2011;108:781-7.

How to cite this article: Jagannath G. Burnout syndrome in healthcare professionals. Telangana $J$ Psychiatry 2020;6(2):105-109. 